\title{
Understanding the "Other": Rethinking Multiculturalism in South Korea through Gadamer's Philosophical Hermeneutics
}

\author{
Jeong-Hee Kim \\ Texas Tech University \\ U.S.A \\ Kyunghee So \\ Seoul National University \\ South Korea
}

ABSTRACT: In this paper, we interrogate the current state of multiculturalism and multicultural education in South Korea and offer a possible theoretical framework that is lacking in the field of multicultural education. We provide three principles of multicultural understanding grounded in Gadamer's philosophical hermeneutics to inform multiculturalism in South Korea and beyond. Based on these principles, we propose that multiculturalism be understood and educated as a way of being, that is, as an ontological multiculturalism, which contributes to a deeper understanding of what it means to be multicultural citizens in the global age.

KEYWORDS: multiculturalism, multicultural education, philosophical hermeneutics, South Korea, global age

Multiculturalism as a Global Phenomenon

Theoretical Framework

The Evolution and Challenges of Multiculturalism in South Korea

Multicultural Education as a Solution?

Implications of Gadamer's Philosophical Hermeneutics for Multiculturalism in South Korea Towards Ontological Multiculturalism

References

Author Contact

Multiculturalism is a global phenomenon today as countries are expected to abide by international standards of human rights and ethnic and cultural diversity (Kymlicka, 2005, 2007; Watson, 2010). Originating in English-speaking countries such as the United States, the United Kingdom, Australia, and Canada, the goal of multiculturalism is to recognize and accept cultural differences and pluralities while valuing the rights of minorities that are marginalized in the mainstream. Hence, multiculturalism is mainly viewed as a "politics of recognition" (Olneck, 2011, p. 678). More specifically, Will Kymlicka (2007), a renowned Canadian 
political philosopher whose expertise is in international politics of diversity, defines multiculturalism as follows:

An umbrella term to cover a wide range of policies designed to provide some level of public recognition, support or accommodation to nondominant ethnocultural groups, whether those groups are 'new' minorities (e.g., immigrant and refugees) or "old" minorities (e.g., historically settled national minorities and indigenous peoples). (p. 16)

As we can see in this definition, the core idea of multiculturalism has political and philosophical dimensions that push countries to implement policies at the institutional level to deal with all forms of oppression. It further aims to provide the protection and promotion of the human rights of ethnic, religious, sexual orientation, and linguistic minorities including indigenous peoples and their communities.

For South Korea, whose multicultural context is the focus of this paper, multiculturalism is a fairly recent phenomenon compared to the West. Although the term multiculturalism first appeared in Korean newspapers in the early 1990s, it was not until the 2000s when South Korea began to view multiculturalism as South Koreans' "own matter" (Ahn, 2012, p. 103). That is, when the term multiculturalism was first introduced in South Korea, it appeared in "brief world news" reports and it did not necessarily reflect Korean society (Ahn, 2012). At that time, South Korea still remained an ethnically and culturally "homogenous" society, as reflected in Kymlicka's (1998) two-decade-old statement, "Most countries today are culturally diverse except for Iceland and South Korea" (p. 1). However, entering the $21^{\text {st }}$ century, Korean society began to diversify with an increasing number of "foreigners" and immigrants, which calls for a more serious discussion of multiculturalism as its own social issue. According to the Korean Ministry of the Interior (2015, www.moi.go.kr), about 1.7 million foreigners (non-Koreans) are currently living in South Korea, a nearly 30 times increase since the 1990s. South Korea is now rapidly becoming a diverse society, experiencing the increasing global trend of multiculturalism.

In order to address the rapid changes in the make-up of the Korean population, the Korean government has been making efforts to establish a variety of multicultural policies to meet both international standards as well as national needs and concerns. Since the 2000s, there has also been a proliferation of publications along with political and scholarly debates on diversity, multicultural issues, and multicultural education to address those issues (Ahn, 2012). Despite the local and national efforts to address the societal change, the issue of multiculturalism, however, has been a social, political, and educational problem in South Korea for quite some time. For example, research indicates that Korean multiculturalism remains focused on cultural and linguistic maintenance and celebrations, while ethnic minorities in South Korea experience inequalities, marginalization, discrimination, and racism, including micro-aggressions that send subtle denigrating messages to ethnic minorities in everyday exchanges (see, for example, Ahn, 2012; Appiah, 2006; Kang, 2010; Mo \& Hwang, 2007; Olneck, 2011). In addition, Korean multiculturalism is criticized for embodying the reified otherness of migrants in their practice of multiculturalism (Chang, 2015). That is, 
ethnic minorities or non-Koreans are positioned as "other" or deviations from the Korean norm. This othering practice creates an "us versus them" dichotomy, perpetuating unequal relationships between the dominant Koreans and the immigrants (Appiah, 2006; Won, 2008). There is also a lack of the conceptual sophistication needed to deal constructively with issues of diversity (Kymlicka, 2007). Indeed, theoretical discussions about multiculturalism and multicultural issues have until recently rarely taken place in South Korea (Ahn, 2012).

In this paper, then, we attempt to contribute to theoretical discussions about Korean multiculturalism in an effort to find ways to rethink its practice. Using Gadamer's philosophical hermeneutics as our theoretical framework, we suggest that, to promote social justice, multiculturalism be practiced as a way of being and understanding the "other." In so doing, we hope to contribute to a deeper understanding of what it means to be multicultural Koreans or world citizens in a changing, diverse, and global age. More important, however, it is our aim to inspire any reader who is interested in multiculturalism and multicultural education to consider the importance of practicing multiculturalism as a way of being and a way of understanding the other.

In the following, we discuss our theoretical framework, Gadamer's philosophical hermeneutics, through which we interrogate the current state of diversity and multiculturalism in South Korea.

\section{Theoretical Framework: Gadamer's Philosophical Hermeneutics}

We draw upon Gadamer's philosophical hermeneutics because it deals with the practice of understanding as a mode of being while challenging our taken-forgranted ideas about prejudice, placing prejudice at the center of understanding.

German philosopher Hans-Georg Gadamer coined the term philosophical hermeneutics to elucidate his theory of understanding, with which Gadamer differentiates himself from neo-Kantians. In his philosophical hermeneutics, Gadamer (1977/2008) explains that understanding takes place in every aspect of our experiences; hence, understanding is not merely a concern of science, but is deeply intertwined in human experience of the world in general. In other words, for Gadamer understanding is a mode of being and a part of who we are, rendering a theory of understanding ontological rather than epistemological and methodological. He emphasizes that understanding is not a problem of method or knowledge; rather, the phenomenon of understanding pervades all human relations to the world, and it also has an independent status within science. To emphasize this, Gadamer (1975/2006) writes, "Understanding is not, in fact, understanding better.... It is enough to say that we understand in a different way, if we understand at all' (p. 296, emphasis in original).

Another important aspect of philosophical hermeneutics is Gadamer's view of the concept of prejudice as a fundamental situation for understanding the other. For Gadamer, our prejudice plays an important role in understanding; he states: 
It is our prejudices that constitute our being. This is a provocative formulation, for I am using it to restore to its rightful place a positive concept of prejudice that was driven out of our linguistic usage by the French and the English Enlightenment. (p. 9)

Considering prejudice the foundation for understanding is a "provocative formulation" indeed, because the concept of prejudice has had a negative connotation since the Enlightenment. In fact, Gadamer criticizes neo-Kantians who value the Cartesian and Enlightenment ideal of the knower's objectivity, in which the knower's prejudice is viewed as something to eliminate because it is believed to distort true understanding. To counter that notion of objectivity, Gadamer rhetorically asks, "Is it the case that the knower can leave his [sic] immediate situation in the present merely by adopting an attitude?" (Linge, 1977/2008, p. xiv). What Gadamer challenges here is the idea that adopting an "attitude" of being objective does not mean that we can be truly objective. That is, a person's sensitivity to understand involves neither neutrality nor his or her subjectivity. Rather, it involves appropriation of one's own fore-meanings and prejudices while being aware of one's own biases. For Gadamer, therefore, all understanding inevitably involves some prejudice, and this recognition is what gives understanding its substance.

To further emphasize the positive concept of prejudice, Gadamer offers a definition of a situation where understanding happens. He states:

The very idea of a situation means that we are not standing outside it and hence are unable to have any objective knowledge of it. We always find ourselves within a situation, and throwing light on it is a task that is never entirely finished. This is also true of the hermeneutic situation-i.e., the situation in which we find ourselves with regard to the tradition that we are trying to understand. (p. 301)

Therefore, when we try to understand the other, we are in a (hermeneutic) situation in which we bring our prejudices with us; hence it is impossible to leave our prejudices outside the hermeneutic situation and be objective. Thus, for Gadamer, prejudices are not considered a false judgment; rather, "prejudices are biases of our openness to the world. They are simply conditions whereby we experience something" (Gadamer, 1977/2008, p. 9). In fact, prejudices are an enabling condition that helps us understand instead of hindering our understanding.

Gadamer (1975/2006) connects this hermeneutic situation with the concept of horizon, which is another important concept of his philosophical hermeneutics. He posits:

The concept of "horizon" suggests itself because it expresses the superior breadth of vision that the person who is trying to understand must have. To acquire a horizon means that one learns to look beyond what is close at hand-not in order to look away from it but to see it better, within a larger whole and in truer proportion. (p. 304)

Here, Gadamer suggests that acquiring a horizon that contains his or her 
prejudices is important although we should not be bound by it in order to understand. Rather, with the horizon, a "standpoint that limits the possibility of vision" (p. 301), we need to learn to look beyond what is close at hand, e.g., prejudice, or taken-for-granted ideas, in order to see things better within a larger whole. Hence, a requirement for one's understanding includes an ability to place ourselves in the other situation by acknowledging the otherness of the other (Gadamer, 1975/2006).

To recap Gadamer's philosophical hermeneutics, understanding begins when the person genuinely opens him or herself to the situation by revealing his/her prejudice because "it is the tyranny of hidden prejudices that makes us deaf to what speaks to us in tradition" (Gadamer, 1975/2006, p. 272). When we open ourselves to the other's horizon, we confront the otherness of the other, rendering a "collision" between different viewpoints, through which understanding takes place. That is, a collision with the other's horizons can take place when we reveal our "hidden prejudices" to the other, and it is through this "collision" that we can be aware of our own deep-seated assumptions and prejudices, which would otherwise remain unnoticed (Linge, 1977/2008). It is in this process of a collision between the different horizons that we can continually test all our prejudices, which in turn, leads to a fusion of horizons. Hence, the result of understanding should always culminate in the fusion of the different horizons that people possess.

Are there, then, any useful ideas in philosophical hermeneutics that we can employ to understand and inform multiculturalism in South Korea? How does it inform us to understand the situation of multiculturalism in South Korea? To help us address these questions, we take a look at Korean multiculturalism, including its evolution and challenges.

\section{The Evolution and Challenges of Korean Multiculturalism}

Traditionally, South Korea is a country that takes much pride in being an ethnically, culturally, and linguistically homogenous society. For Koreans, being mono-cultural, mono-ethnic, and mono-lingual is a paramount factor that constitutes "Koreanness," identified as national identity. Korean nationalism has become a symbol of Korean pride, independence, freedom, and togetherness, especially after 30 years of colonization by Japan and the Korean War that divided the country by agreement between the external forces including the United States and Union of Soviet Socialist Republics. Korean nationalism has worked as an "effective ideological tool for enhancing social cohesion and advancing economic development" (Hong \& Halvorsen, 2014, p. 255). Similarly, Olneck (2011) states:

Belief in Korea as historically ethnically homogeneous, and a concomitant belief in the distinctiveness and superiority of Korean culture, constituted a prevailing ethnic nationalism that was an institutionalized value, and conveyed explicitly, including in education curricula. (p. 676) 
Indeed, the Korean pride that came with "superiority" toward their own culture and race has played an important role in keeping Koreans together and defining themselves. However, as "Koreanness" favors loyalty to the Korean, exclusion of others rather than inclusion has been pervasive in the society (Appiah, 2006; Won, 2008), preventing many Koreans from developing embracing attitudes toward foreigners and/or immigrants as part of their society (Hong \& Halvorsen, 2014).

It was in the early 2000s when the homogenous nature of the Korean society slowly began to change. As the country's economy was improving, more and more Koreans avoided certain occupations especially the so-called, 3-D (difficult, dirty and dangerous) unskilled manual jobs, such as factory labor, restaurant work, and cleaning (A. Kim, 2009; Seol, 2011). To address the shortage of the workforce in these areas, South Korea began systematically welcoming foreign workers in order to meet the growing demand for such labor jobs. For example, there were approximately 639,000 migrant workers in South Korea in 2008, from China, Vietnam, Thailand, Cambodia, and the Philippines (A. Kim, 2009). More recently, foreign migrant workers have come from such countries as Russia, Pakistan, India, Uzbekistan, Brazil, and Nigeria (A. Kim, 2009). The group of migrant workers continues to grow in size and permanence, turning South Korea multiethnically, linguistically, and culturally diverse.

In addition to the continuing influx of foreign laborers, there is another factor that contributes to the emergence of multicultural, multiethnic Korea. Due to the bride shortage in rural areas, foreign brides began to emigrate from other Asian countries such as China (66.2\%), Vietnam (18.7\%), Japan (4\%), the Philippines (3.2\%), Mongolia (1.8\%), Uzbekistan (1.1\%), and Thailand (0.9\%) (Won, 2008). Approximately $36 \%$ of men in the rural areas who got married in 2005 had foreign brides (A. Kim, 2009). These international marriages in South Korea rose from less than $4 \%$ of all new marriages in 2000 to $12 \%$ in 2006 (Kamiya \& Lee, 2009), which adds to a growing number of bi-racial or bi-ethnic children in schools. According to the Korean Ministry of Education (2015), while there has been a decrease of 200,000 a year in the number of students enrolled in K-12 schools, the number of bi-racial students has increased by 6,000 every year.

The increase in the number of foreigners and immigrants including migrant workers, foreign brides, professional foreign workers, and other ethnic minorities such as Korea-defector families and Hwa-gyeo (the Chinese who live in South Korea, see Won, 2008) marks a "significant departure from ethnically homogeneous Korea" (A. Kim, 2009, p. 71). This departure from monoculturalism to a diverse, multicultural society has placed South Korea at a critical juncture for carefully deliberating what it means for Koreans to live in a diverse society that goes beyond mere celebrations of damunhwa (multiculturalism).

In response to such changes, the Korean government has undertaken various multicultural policy changes utilizing the concept of multiculturalism, including terms like "awareness" and "understanding" of immigrants and of multiethnic conditions (Olneck, 2011). The goal is to improve the "intercultural sensitivity of the Korean public and reduce prejudice and discrimination against 
foreign brides and their children" (Oh et al., 2011, p. 25). In 2006, for example, multiculturalism became the "national agenda" (Mo, 2009) as the "Plan for Promoting the Social Integration of Migrant Women, Biracial People, and Immigrants" was announced as the first governmental plan to integrate and develop multicultural society (Ahn, 2012). In addition, in March 2008, a "Public Policy to Support for Multicultural Families" was provided to deal with multicultural issues more specifically and efficiently (Choi, 2014). As a result, many multicultural policies and programs have been established, including the promotion of crosscultural education programs, changes to immigration legislation, and the promotion of tolerance and acceptance of people who are non-Koreans living in South Korea (Olneck, 2011; Watson, 2010). In doing so, South Korea has attempted to improve the country's democratic credentials which will allow the country to better compete in the global market (A. Kim, 2009; Olneck, 2011; Watson, 2010). It is obvious that the significance of multiculturalism has been recognized at the national policy level in South Korea in response to the global changes that will "define the present and future economic, security and cultural national strength of South Korea" (Watson, 2010, p. 337).

However, multiculturalism in South Korea is still at an inchoate stage with many concerns and challenges regarding the directions of multicultural policies (Ahn, 2012; Choi, 2014). For example, Kim (2012) points out that multicultural policies to support immigrant families are limiting and restrictive due to their assimilationist approach. Migrant workers, immigrants, and minorities in schools as well as in the society are subject to discrimination and exclusion in the monoethnic environment, not to mention that their universal human rights are often violated (Hong \& Halvorsen, 2014; Kang, 2010; Olneck, 2011; Watson, 2010; Won, 2008).

The main culprit for prohibiting Koreans from fully embracing diversity and multiculturalism is attributed to Koreans' long-held nationalism and ethnocentrism (Kang, 2010; Kim, 2006; Kong, Yoon, \& Yu, 2010; Olneck, 2011; Watson, 2010; Yoon, 2007). Such a national identity, seemingly characterized as ethnocentrism, is a double-edged sword. On the one hand, it is what brings Koreans together with a strong cohesive sentiment of what it means to be Korean. That is, the long-held nationalism and ethnocentrism is believed to be what has sustained the Koreans as who they are in the changing world. However, it also works as a barrier for Koreans to embrace diversity fully, positioning migrant workers, immigrants, refugees, or non-Koreans as "Other" and a threat to the sustainability of South Korean culture. The nationalistic ideology makes Koreans feel that their culture and identity need to be protected from foreign forces, exacerbating their xenophobia. Hence, many Koreans are reluctant, if not resentful and resistant, to be "mixed" with other races and ethnicities, even though they believe that they are living in an era of globalization (Appiah, 2006).

Another challenge is that Korean multiculturalism is a state-led response to global changes, and multicultural policies were often used by political parties as a political tool to strengthen the present and future economic and security of South Korea in the global environment (Watson, 2010). That is, according to Watson, this 
state-led multiculturalism was born "out of expediency rather than principles" and driven by the sense of "having to be" rather than "wanting to be" multicultural ( $p$. 344). Hence, the state-led multiculturalism in South Korea tends to render current multiculturalism discourse mere political rhetoric and slogan rather than a way to transform the society and to meet the interests and rights of migrant workers and immigrants (Ahn, 2012). With these major challenges, Korean multiculturalism has increasingly been at odds with global multicultural developments (Watson, 2010). For example, in 2006, South Korea was identified by the United Nations Committee for the Elimination of Racial Discrimination as lacking appropriate measures and mechanisms for dealing with non-Koreans (Ahn, 2012; Watson, 2011).

\section{Multicultural Education as a Solution?}

The challenges of Korean multiculturalism are affecting schools in South Korea. The increasing number of immigrants and their school-aged children experience discrimination, bullying, and micro-aggressions, which have surfaced as an important education issue to be addressed. Korean researchers, policy makers, and educators, therefore, have turned to multicultural education as an effective way to improve the lives and experiences of the increasing number of immigrants and their children in education (Mo \& Hwang, 2007). For instance, in 2007, the Ministry of Education and Human Resources Development undertook textbook revisions to incorporate multicultural education into elementary, middle, and high school curricula. These changes indicate "a different way of life of foreigners or difficulties of mixed race children" (N. Kim, 2009, as cited in Olneck, 2011, p. 675). This version of Korea's national curriculum suggests: (a) support for immigrant families is indispensable; (b) multiculturalism should be used as a crosscurricular theme and incorporated into the school curriculum as well as extracurricular activities; (c) terms such as mono-race and mono-ethnicity, or "one blood" of the Korean race (Hanminjok) should be deemphasized; and (d) embracing an understanding of diversity and multiculturalism should be highly encouraged (So, Lee, Park, \& Kang, 2014). Furthermore, central characteristics of multiculturalism such as tolerance, acceptance, and respect (Nieto, 2004) have been recognized in the new curriculum standards in an attempt to replace monoethnocentrism with notions of cultural diversity and multiculturalism. Some examples include:

- Ethics Curriculum: Overcoming prejudices and presenting tolerance: Students have a right understanding of diversity. They should accept, tolerate, and respect different cultures. (Ministry of Education and Human Resources Development 2007, p. 10)

- Social Studies Curriculum: Different Cultures in Different Regions: Students should understand and respect different cultures in the world. Students learn and respect diversity through their interests in sports, movies, arts, and festivals, hosted in the world. (Ministry of Education and Human Resources Development 2007, p. 21) 
Another national curriculum change took place in 2009, which further propelled an increase in the content on multiculturalism. Schools were encouraged to develop various multicultural education programs including Korean language programs, mentoring systems, and after-school programs devised to help "multicultural children and their families to learn Korean language and culture, and thus facilitate integration of multicultural students into schools" (Cho, 2010, p. 192). Teachers were offered professional development opportunities to help meet the educational needs of migrant children in classrooms (Kang, 2010), incorporating additional multicultural curriculum into each level of education from preschool to university (Oh et al., 2011), and raising awareness about the racial bias and prejudices that minority students face in Korea (Kang, 2010). Efforts were also made to help educators and students be more cognizant of diversity and multicultural education (Mo \& Hwang, 2007; Olneck, 2011). In the most recent 2015 curriculum reform, national interests in multicultural education have been more explicitly strengthened to include not only race and ethnicity but also gender, religion, and class.

Given the last three national curriculum changes that put an emphasis on multicultural education, it is clear that multicultural education is viewed as "the best answer to the educational problems of children not belonging to the majority cultural group" (Kang, 2010, p. 292). What is not clear, however, is how effective multicultural education has been (Hong \& Halvorsen, 2014).

One of the concerns around multicultural education is that Korean teachers are not yet confident enough to teach multicultural issues. Teachers themselves think that they lack the necessary knowledge and skills to teach multicultural education effectively (Mo \& Hwang, 2007). Another concern is that despite curriculum reform efforts to integrate multiculturalism into schools, Korean multicultural education still reflects a monocultural, ethnocentric curriculum with assimilationist practices and largely ignores the experiences, cultures, and histories of ethnic minorities in South Korea (Kang, 2010). In addition, multicultural education programs are practiced as "add-on" or special programs for minority students through exclusion and separation from the mainstream education (Banks \& Banks, 2007; Olneck, 2011). This kind of practice leads to labeling and stigmatization, falsely reinforcing a sense of superiority among mainstream Korean students and treating immigrant children as "Other" (Cho, 2010; Kang, 2010). As a result, immigrant children continue to deal with alienation, marginalization, and segregation from "fellow pupils, teachers, community people, and even their own relatives" (Kang, 2010, p. 287). At the same time, they suffer from low self-esteem and the fear of mixing together with the community (Kang, 2010). Multicultural education in South Korea seems to have a long way to go in order to transform monocultural and ethnocentric attitudes among students, teachers, and parents; it is failing to alleviate the concerns that Korean multiculturalism faces. 


\section{Implications of Gadamer's Philosophical Hermeneutics for Multiculturalism in South Korea}

How, then, can the theoretical framework of Gadamer's philosophical hermeneutics be useful in understanding the challenges that Korean multiculturalism faces? How can it contribute to theoretical discussions that would defy the continuous exclusion and marginalization of immigrants in South Korea? How can it inform us of the philosophy of multiculturalism and help us exercise multiculturalism as a way of being and understanding? Simply speaking, in what ways can Gadamer's philosophical hermeneutics broaden our horizons?

Since understanding the other is paramount in multiculturalism, Gadamer's philosophical hermeneutics can offer insights as its focus is a genuine understanding of the other. Based on our understanding of philosophical hermeneutics, we offer an analysis and synthesis of Korean multiculturalism, while addressing these questions. We provide what we call, three principles of multicultural understanding, which we hope will be incorporated into the philosophy of multiculturalism in South Korea.

First, multicultural understanding is circular. That is, we must understand the whole in terms of the details and the details in terms of the whole. We want to maintain our individualities (diversity) while integrating into the whole society (unity). We want to understand "the details" of each individual culture, norm, prejudice, language, and uniqueness, while embracing the diverse society as "the whole." This movement of understanding is "circular" (Gadamer, 1975/2006, p. 291) in that understanding is supposed to move harmoniously "from the whole to the part and back to the whole" (p. 291), creating a "hermeneutic circle." Hence, Gadamer states, "The harmony of all the details with the whole is the criterion of correct understanding. The failure to achieve this harmony means that understanding has failed" (p. 291).

By embracing this notion of understanding as circular, Koreans do not need to desert their strong national identity, their history, or culture. They can use the cohesive power of national identity to sustain the society as a whole and, at the same time, acknowledge how different cultural and ethnic groups enrich the Korean society as the minority groups become the part of complex threads in the society. Rather than viewing the details of migrant workers, immigrants, refugees, or non-Koreans as a threat to the integrity of Korean culture, Koreans can appreciate the immigrants' contributions to a diverse society. When this kind of hermeneutic circle takes place, the so-called, damunwha, Korean multiculturalism, can create a "new, ongoing 'We'" (Modood, 2011, p. 3) with all the people that make up the country, including both mono-ethnic Koreans and immigrants. In this way, Koreans may lose the sense of cultural "superiority" (Olneck, 2011) while expanding the unity of Koreanness, not as an exclusion of others (Appiah, 2006; Won, 2008) but as a way to accept foreigners and/or immigrants both centrifugally and centripetally. 
Second, multicultural understanding happens with critical empathy. Understanding another person takes place when we attempt to "discover where he [sic] is coming from" (Gadamer, 1975/2006, p. 302). Gadamer calls it a "legitimate hermeneutical requirement" (p. 302). That is, we must place ourselves in the other's situation in order to understand it. It is an "art of understanding" ( $p$. 303) if we can say that we have learned to transpose ourselves into the other. However, this does not mean that we must reach an agreement with the other. Nor does it mean that we have to discard "ourselves." In fact, the full meaning of "transposing ourselves" is realized when we bring our own prejudices, identities, and histories to an understanding, while suspending our privilege or our sense of superiority to the other.

If Koreans have such an empathy through which they can put themselves in the immigrant's shoes while seeing beyond their own immediate interests and values, Korean multiculturalism could be transformed in a way nobody has yet imagined. It would be necessary for Koreans to develop more empathic understanding for migrant workers who would willingly take the unskilled manual jobs that Koreans are reluctant to take; foreign brides who voluntarily immigrate to marry Korean men in rural areas; defector families who have fled from North Korea to pursue freedom; and school-aged children of the immigrants, who continuously experience discrimination, bullying, racism, and oppression in schools. They all coexist to benefit the Koreans and their society.

Although empathy is a must-have characteristic of a person who tries to understand the lives of others beyond his/her local region or group (Nussbaum, 1998; von Wright, 2002), empathy itself is not enough. Empathy without critical analysis may promote a "false sense of involvement" (Rosenberg, as cited in Watkins \& Noble, 2014, p. 57). It may shift attention away from the institutional problems of systematic oppression and injustice against minorities. For example, as noted earlier, in South Korea, many multicultural policies and programs have been established at the national level, but researchers have raised concerns about the directions of such multicultural policies (Choi, 2014). It should also be noted that Korean multicultural policies still use an assimilationist approach that limits the immigrants' universal human rights (Kim, 2012; Hong \& Halvorsen, 2014; Kang, 2010; Olneck, 2011; Watson, 2010; Won, 2008). Critical empathy would help a multicultural person recognize the institutional problems that create inequality and inequity. Hence, critical empathy needs to be fostered as a way to examine reductive and self-serving forms of cultural diversity at the institutional level or false sense of success in multiculturalism. With critical empathy, Koreans can help multiculturalism surpass the superficial level of celebration and stop being mere political rhetoric or slogan.

Third, multicultural understanding promotes an individual horizon and a fusion of the horizons. A multicultural person should have a "horizon" to be able to understand the "Other." According to Gadamer, as discussed earlier, a person who does not have a horizon cannot see far enough and will likely overvalue her own values and norms. This sounds easier said than done as we tend to be affected by, and value, what is nearest to us, e.g., what we have been doing, thinking, and 
saying for all of our lives. We value our own prejudices, whether they are historical, cultural, geographical, or political. However, Gadamer has given us some consolation with his notion of the "hermeneutical situation." That is, when we try to understand the "Other," we are in a hermeneutic situation where we bring our prejudices with us, and this hermeneutic situation is what constitutes one's horizon. Gadamer also reminds us:

But now it is important to avoid the error of thinking that the horizon of the present consists of a fixed set of opinions and valuations, and that the otherness of the past can be foregrounded from it as from a fixed ground. (p. 305)

The fact that our prejudices are a necessary condition for hermeneutical situation and that they make up our horizon does not mean that we should view our own prejudices as fixed and adopt them as a superior hermeneutic condition. As a matter of fact, Gadamer states that our horizon is "continually in the process of being formed because we are continually having to test all our prejudices" ( $p$. 305). Therefore, a horizon as the range of one's vision can be narrowed or expanded, and thus open up to new horizons. When we open our horizons to others, there may be a collision between the different viewpoints. However, it is when we let our prejudices collide with each other that we can adjust our horizons, thus leading to a fusion of horizons.

Perhaps, then, the Koreans' long-held nationalism or ethnocentrism that prohibits them from fully embracing diversity and multiculturalism (Kang, 2010; Kim, 2006; Kong et al., 2010; Olneck, 2011; Watson, 2010; Yoon, 2007) needs to be tested against the beliefs and norms that immigrants and minorities possess. As discussed earlier, Koreans are proud of being ethnically homogeneous (Hong \& Halvorsen, 2014; Olneck, 2011). Koreans' xenophobia produces insidious racism due to the fear of being "mixed" with other races and ethnicities (Appiah, 2006; Mo \& Hwang, 2007). Gadamer would say that this is an example of a "closed horizon" (p. 303), in which one's culture and ideology are encapsulated in abstraction. However, Gadamer would also say that a true horizon is something "into which we move and that moves with us" (p. 303). Therefore, one's horizon is supposed to be flexible, open, and expandable, so that one's horizon can fuse with others' horizons. Koreans who acquire such a horizon may recognize the limits of national identity or the mono-ethnic "Koreanness." They are supposed to let their prejudices collide with those of the immigrants and willingly work on a fusion of horizons. In so doing, they can adjust their horizons and participate in a "continual remaking of national identity" (Modood, 2011, p. 3).

\section{Towards Ontological Multiculturalism: A Way of Being and Understanding}

In this article, drawing upon Gadamer's philosophical hermeneutics, we intend to contribute to a theoretical dialogue about multiculturalism in South Korea. 
We further propose that three principles of multicultural understanding become the theoretical foundation of multiculturalism. To reiterate, the three principles are:

- Multicultural understanding is circular.

- Multicultural understanding happens with critical empathy.

- Multicultural understanding promotes an individual horizon and a fusion of the horizons.

Before he theorized his theory of understanding, philosophical hermeneutics, in his seminal book Truth and Method (1975/2006), Gadamer began with the question, "How is understanding possible?" For him, this is a question "which precedes any action of understanding on the part of subjectivity, including the methodical activity of the 'interpretive sciences' and their norms and rules" ( $p$. xxvii). So, Gadamer clearly states that "understanding is not just one of the various possible behaviors of the subject but the mode of being" ( $p$. xxvii, emphasis added). According to him, an understanding as a mode of being is what makes an act of understanding "comprehensive and universal" (p. xxvii). Hence, we suggest that multiculturalism informed by Gadamer's philosophical hermeneutics be practiced as a way of being in the global world. An ontological multiculturalism that incorporates three principles of multicultural understanding is not just a concept; rather, it is an everyday practice that South Koreans can adopt.

Ontological multiculturalism would also have implications for multicultural education in South Korea. As stated earlier, multicultural education programs, instead of being fully integrated into the mainstream education, tend to be practiced as "add-on" or special programs for minority students (Banks \& Banks, 2007; Olneck, 2011). At the same time children of immigrants continue to be treated as "Other" and suffer from stigmatization and marginalization (Cho et al., 2010; Kang, 2010). Multicultural understanding that is circular, which happens with critical empathy and promotes a fusion of individual horizons, can inform teachers and students of what it means to be multicultural citizens (Kymlicka, 2001) or world citizens (Nussbaum, 1998). For example, Nussbaum posits that it is through education that children's democratic citizenship can be cultivated, but it has to start as early as possible. She states:

Education for world citizenship needs to begin early. As soon as children engage in storytelling, they can tell stories about other lands and other peoples. A curriculum for world citizenship would do well to begin with the first grade, where children can learn...that people have many traditions and ways of thinking. (p. 69)

Similarly, multicultural education should be "basic education for all students" (Nieto, 2004, p. 346) and cannot be disconnected from the everyday lives of students. Multicultural education rejects racism and other forms of discrimination in school and society; it is education for social justice (Banks \& Banks, 2007; Grant \& Sleeter, 2006; Nieto, 2004). Multicultural education in South Korea that embodies ontological multiculturalism can be taught as "basic education for all 
students," including children of the immigrants, and thus, become education for social justice.

In closing, we would like to mention that we are aware of the gap between what we claim to argue, i.e., ontological multiculturalism, and the reality in South Korea. This awareness, what Gadamer calls "hermeneutic consciousness," must be "awakened and kept awake," so that we can recognize that our claim has something "chimerical and unreal about it" (p. xxxiv). As such, we understand that our claim to exercise multiculturalism and multicultural education as a way of being and understanding may be a tall order, given the current multicultural context fraught with all the challenges to overcome in South Korea denoted earlier in the article. However, with the hermeneutic consciousness about our claim, we ultimately hope that ontological multiculturalism will be practiced elsewhere beyond South Korea. We hope that countries in the West or East that experience an influx of immigrants and refugees will learn from this Korean example and examine their own multicultural understanding. The ontological multiculturalism we discuss in this article should be a global imperative in which the voices of immigrants and refugees are integrated into the web of the global society as basic human rights.

\section{References}

Ahn, J. H. (2012). Transforming Korea into a multicultural society: Reception of multiculturalism discourse and its discursive disposition in Korea. Asian Ethnicity, 13(1), 97-109.

Appiah, K. A. (2006) Cosmopolitanism: Ethics in a world of strangers. New York, NY: W. W. Norton.

Banks, J. A., \& Banks, C. A. (Eds.). (2007). Multicultural education: Issues and perspectives (6th ed.). Hoboken, NJ: Wiley.

Chang, I. (2015). An exploration of school curriculum for multicultural education. Journal of Curriculum Studies, 33(2), 45-70.

Choi, S. (2014). Education to enhance social justice: Meanings of multicultural education and approaches for multicultural teacher education. The Journal of Curriculum Studies, 32(3), 123-150.

Gadamer, H. G. (1975/2006). Truth and method (2nd ed.) (J. Weinsheimer \& D. Marshall, Trans.). New York, NY: Continuum.

Gadamer, H. G. (1977/2008). Philosophical hermeneutics Berkeley, CA: University of California Press.

Grant, C. A., \& Sleeter, C. E. (2006). Doing multicultural education for achievement and equity. New York, NY: Routledge.

Hong, W. P., \& Halvorsen, A. (2014). Teaching the USA in South Korean secondary classrooms: The curriculum of 'the superior other.' Journal of Curriculum Studies, 46 (2), 249-275. 
Kamiya, H., \& Lee, C. W. (2009). International marriage migrants to rural areas in South Korea and Japan: A comparative analysis. Geographical Review of Japan Series B, 81, 60-67.

Kang, S. W. (2010) Multicultural education and the rights to education of migrant children in South Korea. Educational Review, 62 (3), 287-300.

Kim, A. E. (2009). Global migration and South Korea: Foreign workers, foreign brides and the making of a multicultural society. Ethnic and Racial studies, 32(1), 70-92.

Kim, W. S. (2006) Globalization and nationalism: A Korean experience. Korean Journal for Citizenship Education, 11 (2), 97-122.

Kong, D., Yoon, K., \& Yu, S. (2010). The social dimensions of immigration in Korea. Journal of Contemporary Asia, 40(2), 252-274.

Kymlicka, W. (1998). Multicultural citizenship. New York, NY: Oxford University Press.

Kymlicka, W. (2001). Politics in the vernacular: Nationalism, multiculturalism, and citizenship. Oxford, UK: Oxford University Press.

Kymlicka, W. (2005). Liberal multiculturalism: Western models, global trends, and Asian debates. In W. Kymlicka \& B. He (Eds.), Multiculturalism in Asia (pp. 2255). New York, NY: Oxford University Press.

Kymlicka, W. (2007). Multicultural odysseys: Navigating the new international politics of diversity. Oxford, UK: Oxford University Press.

Ministry of Education. (2015). The 2015 revised Korean national curriculum. Seoul: Ministry of Education.

Ministry of Education \& Human Resources Development. (2007). The 2007 revised Korean national curriculum. Seoul: Ministry of Education \& Human Resources Development.

Korean Ministry of the Interior. (2015). Retrieved from www.moi.go.kr.

Mo, K. W (2009). Policies and directions of multicultural teacher education in Korea. The Journal of Korean Teacher Education, 26(4), 245-270.

Mo, K. W., \& Hwang, H. W. (2007). Social studies teachers' perception of multicultural education and its implications on teacher education programs. The Journal of Korean Teacher Education, 24(2), 199-219.

Modood, T. (2011). Multiculturalism and integration: Struggling with confusions. European University Institute, Italy. Retrieved from http://www.coe.int/t/dg4/cultureheritage/mars/source/resources/references/ot hers/38\%20-\%20Multiculturalisme\%20and\%20Integration\%20-\%20Modood $\% 202011$.pdf.

Nieto, S. (2004). Affirming diversity: The sociopolitical context of multicultural education (4th ed.). Boston, MA: Pearson. 
Nussbaum, M. C. (1998). Cultivating humanity: A classical defense of reform in liberal education. Cambridge, MA: Harvard University Press.

Oh, J., Kang, D., Shin, J., Lee, S., Lee, S. B., \& Chung, K. (2011). Migration profile of the Republic of Korea. IOM MRTC Research Report Series, No. 2011-01. IOM Migration Research and Training Centre. Goyang-si, Republic of Korea.

Olneck, M. R. (2011) Facing multiculturalism's challenge in Korean education and society. Asia Pacific Education Review, 12(4), 675-690.

Seol, D. H. (2011). Ethnic enclaves in Korean cities: Formation, residential patterns and communal features. In T. C. E. Wong \& J. Rigg (Eds.). Asian cities, migrant labor and contested spaces (pp. 133-155). London, UK: Routledge.

So, K., Lee, S., Park, J., \& Kang, J. (2014). The idea of cosmopolitanism in Korea's national curriculum. Asia Pacific Journal of Education, 34(1), 1-14.

von Wright, M. (2002). Narrative imagination and taking the perspective of others. Studies in Philosophy of Education, 21(4), 407-416.

Watkins, M., \& Noble, G. (2014). Rethinking multiculturalism reassessing multicultural education. Project report number 3 Knowledge translation and action research. University of Western Sydney, Australia. Retrieved from http://www.uws.edu.au/_data/assets/pdf_file/0008/776330/RMRME_Report 3_020415.pdf. Accessed 10 June 2016.

Watson, I. (2010). Multiculturalism in South Korea: A critical assessment. Journal of Contemporary Asia, 40(2), 337-346.

Won, S. Y. (2008). Differentiated inclusion and exclusion of policy for marginalized groups in multicultural age. Korean Public Administration Review, 42(3), 2949.

Yoon, I. J. (2007). The development of South Korea's nationalist discourses and the exploration of alternative nationalism in a global era. Korean Journal of Social Research, 8(1), 5-30.

\section{Author Contact}

Jeong-Hee Kim: jeong-hee.kim@ttu.edu

Texas Tech University, 2500 Broadway, Lubbock, TX 79409

Kyunghee So: sohee@snu.ac.kr

Seoul National University, 1 Gwanak-ro, Gwanak-gu, Seoul, South Korea 